\title{
Effect of Compaction Pressure on Structural and Superconducting Properties of Bi-2223 Superconductors
}

\author{
Kemal Kocabaş • Melis Gökçe • Muhsin Çiftçioğlu • \\ Özlem Bilgili
}

Received: 29 September 2009 / Accepted: 9 October 2009 / Published online: 9 December 2009

(C) Springer Science+Business Media, LLC 2009

\begin{abstract}
In this work, effects of compaction pressure on the structural and superconducting properties of BSCCO ceramic superconductors were investigated. The study was carried out on two systems which were, System I: $\mathrm{Bi}_{1.7} \mathrm{~Pb}_{0.3}$ $\mathrm{Sr}_{2} \mathrm{Ca}_{2} \mathrm{Cu}_{3} \mathrm{O}_{y}$ and System II: $\mathrm{Bi}_{1.6} \mathrm{~Pb}_{0.3} \mathrm{Ag}_{0.1} \mathrm{Sr}_{2} \mathrm{Ca}_{2} \mathrm{Cu}_{3} \mathrm{O}_{y}$, respectively. Ceramic powders were prepared by conventional solid-state reaction method and sintered at $850^{\circ} \mathrm{C}$ after compaction at five different pressures in the $150-750 \mathrm{MPa}$ range. Critical temperatures of samples were determined by resistivity-temperature determinations made by four-point probe method in liquid nitrogen conditions. XRD analysis was conducted by powder X-ray diffraction method. Morphology of the grains present in the samples were determined by using scanning electron microscope (SEM) photographs at $2 \mathrm{~K} \times$ and $2.5 \mathrm{~K} \times$ magnifications for System I and System II, respectively. Sintered densities of the superconducting ceramics were measured by Archimedes water displacement method and unit cell parameters were additionally obtained from XRD data. $T_{\mathrm{c}}$ values for System I was determined to be in the 109-115 K with sample D having the highest $T_{\mathrm{c}}$ of $115 \mathrm{~K}$ while $T_{\mathrm{c}}$ varied in the 104-109 K range and sample B had the highest $T_{\mathrm{c}}$ value of $109 \mathrm{~K}$ for
\end{abstract}

K. Kocabaş $(\varangle) \cdot$ Ö. Bilgili

Physics Department, Faculty of Arts and Science, Dokuz Eylül University, 35160 Buca, İzmir, Turkey

e-mail: kemal.kocabas@deu.edu.tr

M. Gökçe

Physics Department, Faculty of Arts and Science,

Adnan Menderes University, 09010 Aydın, Turkey

M. Çiftçioğlu

Chemical Engineering Department, İzmir Institute of Technology,

35430 Urla, İzmir, Turkey
System II. The transition width, which is a sign of the purity of the samples, was determined to be narrow for both systems. The data obtained from X-ray diffraction measurements have shown that 2223 high- $T_{\mathrm{c}}$ phase was dominant in both systems. The determination of the optimum pellet compaction pressure for BSCCO ceramic superconductors was the main purpose of this work. The results of this work indicated that compaction at around $450 \mathrm{MPa}$ improves the superconducting and structural properties of the BSCCO ceramic superconductors.

Keywords Bi-based superconductors - X-ray diffraction . Compaction pressure $\cdot$ Grain structure

\section{Introduction}

The Bi-2223 based ceramics are considered to be as the most interesting high- $T_{\mathrm{c}}$ superconductors for various reasons, particularly for their rather high critical temperature $T_{\mathrm{c}}$ and their rather high critical current density $J_{\mathrm{c}}$. However, such a chemical system is known to be hard to obtain as a pure phase. It is well known that it is possible to increase the fraction of the so-called $110 \mathrm{~K}$ (2223) phase in the system, where $110 \mathrm{~K}$ is the superconducting critical temperature, by partially substituting lead for bismuth in the $\mathrm{Bi}_{1.6} \mathrm{~Pb}_{0.4} \mathrm{Sr}_{2} \mathrm{Ca}_{2} \mathrm{Cu}_{3} \mathrm{O}_{y}$ composition [1]. The formation of $\mathrm{Bi}(\mathrm{Pb})-2223$ had been studied in air, reduced or partial oxygen pressure and in nitrogen in some detail. In air, the formation of pure $\mathrm{Bi}(\mathrm{Pb})-2223$ encounters two major problems. The lower $T_{\mathrm{c}}(80 \mathrm{~K})$ phase $\mathrm{Bi}_{1.6} \mathrm{~Pb}_{0.4} \mathrm{Sr}_{2} \mathrm{CaCu}_{2} \mathrm{O}_{8}(\mathrm{Bi}(\mathrm{Pb})-$ 2212) formation at the temperatures that the $(\mathrm{Bi}(\mathrm{Pb})-2223)$ phase forms is the first of these problems. The second problem is that $\mathrm{Bi}(\mathrm{Pb})-2212$ is more stable than $\mathrm{Bi}(\mathrm{Pb})-2223$. 
Thus, $\mathrm{Bi}(\mathrm{Pb})-2223$ decomposes to $\mathrm{Bi}(\mathrm{Pb})-2212$ and nonsuperconducting phases at the same temperature it forms on prolonged heating which is due to the fact that $\mathrm{Bi}(\mathrm{Pb})-2223$ is meta-stable at its formation temperature in air [2]. The approval of a material for application in the $\mathrm{Bi}(\mathrm{Pb})-\mathrm{Sr}-\mathrm{Ca}-$ $\mathrm{Cu}-\mathrm{O}$ HTSC system necessitates the ability to control the influence of technologically important processing parameters on its properties. The existence of two basic superconducting phases 2223 and 2212 in the system, extent of formation of the non-superconducting phases, quality of contacts between grains, and the arrangement of grains in space to a certain extent depend on various parameters. The atomic ratio of elements in the structure, method of the homogenization of the structure, compaction pressure of the powders for the 2223 phase formation, time and temperature of the final heat treatment processing step are among these parameters [3]. The grains in the polycrystalline microstructure must orient along a certain direction which often is referred to as texturing for the preparation of high- $T_{\mathrm{c}}$ superconductors with anisotropic physical properties for achieving a large critical current density. The most convenient way of achieving texturing is the application of uniaxial pressure on the ceramic before final annealing.

The results of the work by Tepe et al. [4] have shown that the quality of electrical and structural properties of Bi-2223 bulk superconductors strongly depend on the compaction pressure during pellet formation. Compaction of bulk samples at $400 \mathrm{MPa}$ produces textured grain alignment and causes microstructural modifications which enhances flux pinning and thus increases current carrying capacities.

Mune et al. [5] had found that the grain properties were very similar in all samples but that the $J_{\mathrm{c}}\left(B_{a}\right)$ dependence was very sensitive to the compaction pressure and the experimental data were evaluated within the framework of a three-level superconducting system.

Govea et al. [6] investigated the resistive transition of nearly single-phase $\mathrm{Bi}_{1.65} \mathrm{~Pb}_{0.35} \mathrm{Sr}_{2} \mathrm{Ca}_{2} \mathrm{Cu}_{3} \mathrm{O}_{10+\delta}$ samples subjected to uniaxial compaction at different pressures under low applied magnetic fields. They have found that the dissipation region between the offset temperature, $T_{\text {off }}$, and the onset temperature, $T_{\mathrm{on}}$, are very sensitive to the applied magnetic field and the uniaxial compaction pressure. Their results have shown that increasing the uniaxial compaction pressure improves both the grain connectivity and the degree of texturing in the samples.

Beside Bi-based superconductors, Topal [7] have investigated the effect of compaction pressure on the structural and electrical properties of $\mathrm{TlCaBaCuO}$ superconducting materials. The porosity and the volume fraction of the Tl-2212 phase in the samples prepared with a nominal composition of $\mathrm{Tl}_{2} \mathrm{Ba}_{2} \mathrm{Ca}_{2} \mathrm{Cu}_{3} \mathrm{O}_{10-\delta}$ were found to decrease and the Tl2223 phase content increased with increasing compaction pressure in the above study. It was also observed that the zero resistance temperature $T_{\mathrm{c}}$ (off) increased and the transition width decreased with increasing pellet formation pressure. Transport critical currents of samples increased with increasing temperature as a consequence of improved intergranular couplings [7].

In our previous work, we investigated the effects of $\mathrm{Li}$ substitution on the properties of high-temperature superconductor $\mathrm{Bi}_{1.7} \mathrm{~Pb}_{0.3} \mathrm{Sr}_{2} \mathrm{C}_{2} \mathrm{Cu}_{3-x} \mathrm{Li}_{x} \mathrm{O}_{y}$ pressing of bulk samples at $450 \mathrm{MPa}$. The $\mathrm{X}$-ray diffraction indicated the formation of a large amount of $\mathrm{Bi}-(2223)$ phase along with a minor amount of Bi-(2212) phase. Maximal value of the volume percentage of high- $T_{\mathrm{c}}$ (2223) phase was calculated to be 81 for the sample having Li content $x=0.20$ [8].

The effect of compaction pressure on superconducting properties and microstructure of BSCCO ceramics in two different systems were investigated by using resistivitytemperature determination, X-ray diffraction data, and SEM in the present work.

\section{Experimental Procedure}

Standard solid-state reaction method was used to form (Bi, $\mathrm{Pb})-\mathrm{Sr}-\mathrm{Ca}-\mathrm{Cu}-\mathrm{O}$ ceramics. This method involved the use of pure starting chemicals of $\mathrm{Bi}_{2} \mathrm{O}_{3}, \mathrm{PbO}, \mathrm{SrCO}_{3}, \mathrm{CaCO}_{3}$, $\mathrm{Ag}_{2} \mathrm{O}$ and $\mathrm{CuO}$ powders (Aldrich Chem. Co). The ceramic superconducting samples of $\mathrm{Bi}_{1.7} \mathrm{~Pb}_{0.3} \mathrm{Sr}_{2} \mathrm{Ca}_{2} \mathrm{Cu}_{3} \mathrm{O}_{y}$ (System I) and $\mathrm{Bi}_{1.6} \mathrm{~Pb}_{0.3} \mathrm{Ag}_{0.1} \mathrm{Sr}_{2} \mathrm{Ca}_{2} \mathrm{Cu}_{3} \mathrm{O}_{y}$ (System II) were prepared from appropriate compounds.

Predetermined amounts of powders were mixed and well ground initially. These mixtures were heat treated twice at $800^{\circ} \mathrm{C}$ for $30 \mathrm{~h}$ in alumina crucibles. The heat-treated powders were ground again in a mortar with pestle, and were uniaxially pressed (Graseby Specac) at five different pressures and coded as A (150 MPa), B (300 MPa), C (450 MPa), D (600 MPa), and E (750 MPa). Prepared pellets were $13 \mathrm{~mm}$ in diameter and $1-1.5 \mathrm{~mm}$ in thickness. System I pellets were sintered twice. They were sintered at $850^{\circ} \mathrm{C}$ for $40 \mathrm{~h}$ and at $850^{\circ} \mathrm{C}$ for $250 \mathrm{~h}$ a second time by using $7^{\circ} \mathrm{C} /$ minute heating rate and furnace cooled down to room temperature in air. System II pellets were sintered at $850^{\circ} \mathrm{C}$ for $250 \mathrm{~h}$ by using $7^{\circ} \mathrm{C} /$ minute heating rate and furnace cooled in air down to room temperature. A $1200^{\circ} \mathrm{C}$ Nabertherm furnace was used for all heat treatments in this work.

The dc resistivity of samples as a function of temperature was measured by means of a standard four-point probe method with silver point contacts. XRD patterns of System I ceramics in the $2 \theta=2^{\circ}-60^{\circ}$ range was obtained by using $\mathrm{CuK}_{\alpha}$ radiation and Rigaku D Max 3C XRD. Diffraction patterns of System II ceramics were obtained by using $X$ pert Pro Philips Analytical diffractometer in the $2 \theta=3^{\circ}-55^{\circ}$ range with $\mathrm{CuK}_{\alpha}$ radiation. The SEM microphotographs of 
System I were taken by using JEOL JJXA733 microscope and the SEM microphotographs of System II were taken by using Philips XL SFEG 30 SEM.

\section{Results and Discussion}

\section{System I}

The temperature dependence of the resistances for all pellets is given in Fig. 1. All samples display a metallic character above onset temperature, which is defined as the temperature where resistance temperature plot deviates from linearity. The onset temperatures of the samples were $120 \mathrm{~K}$, $121 \mathrm{~K}, 124 \mathrm{~K}, 124 \mathrm{~K}$ and $120 \mathrm{~K}$, respectively. The critical temperatures, e.g. zero resistance temperatures, were determined as $109 \mathrm{~K}, 110 \mathrm{~K}, 114 \mathrm{~K}, 115 \mathrm{~K}$ and $109 \mathrm{~K}$, respectively, and are further tabulated in Table 1.

The resistance drop occurred in a single step implying that the samples are mainly composed of a single phase. The Bi-2223 phase has $110 \mathrm{~K}$ offset temperature. The obtained results are close to this value. The highest onset and offset temperatures were determined for C (450 MPa) and D (600 MPa) pellets and it is possible to state that up to a certain level compaction pressure improves the formation of the high- $T_{\mathrm{c}}$ phase. The transition width $(\Delta T)$, which is

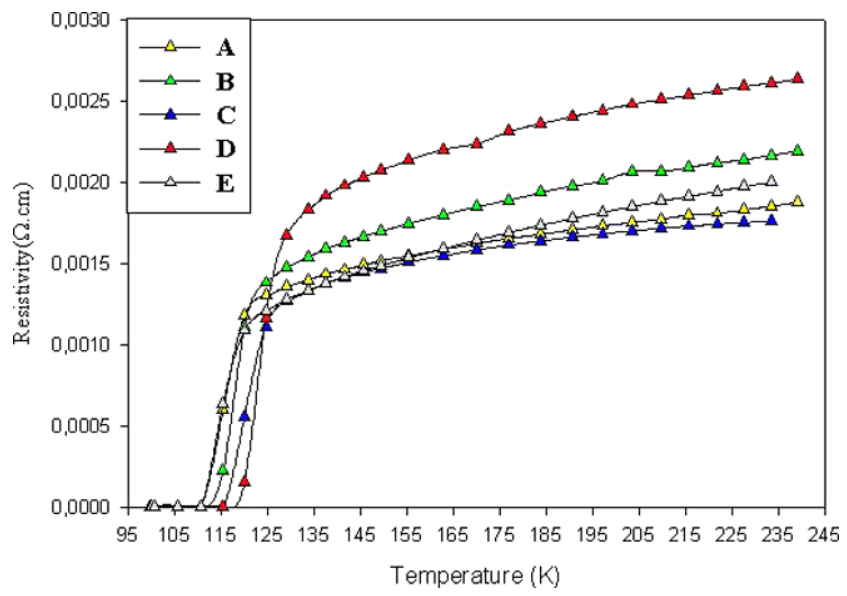

Fig. 1 Resistivity versus temperature for System I, A (150 MPa), $B$ ( $300 \mathrm{MPa}), C(450 \mathrm{MPa}), D(600 \mathrm{MPa}), E(750 \mathrm{MPa})$ a parameter of the phase purity, was determined as $11 \mathrm{~K}$, $11 \mathrm{~K}, 10 \mathrm{~K}, 9 \mathrm{~K}$ and $11 \mathrm{~K}$, respectively. The variation of $(\Delta T)$ with compaction pressure is further plotted in Fig. 2 and the presence of the narrowest transition width for samples $\mathrm{C}$ and $\mathrm{D}$ was in agreement with the determined $T_{\mathrm{c}}$ values. A sharp decrease in resistivity was observed with the increase of compaction pressure from 300 to $450 \mathrm{MPa}$. This was attributed to the predominant effect of compaction in the pellet through grain growth in this pressure range [9].

There is an increase in the resistivity above $450 \mathrm{MPa}$ compaction pressure, which maybe due to presence of fine grains. The resistivity may also increase due to the weakening of the intergrain links above $450 \mathrm{MPa}$. Sample D (600 MPa) with the highest resistivity also had the highest onset and offset temperatures. Finally, the increase of compaction pressure up to $750 \mathrm{MPa}$ shows a decrease in resistivity, due to extensive grain breakages. The results obtained by Pintu Sen et al. [10], in $\mathrm{Bi}_{1.84} \mathrm{~Pb}_{0.34} \mathrm{Sr}_{1.91} \mathrm{Ca}_{2.03} \mathrm{Cu}_{3.06} \mathrm{O}_{10+\delta}$ composition, indicated that there was no appreciable change in excess oxygen content hence onset temperature.

The pressure responsible for the highest degree of texturing is different in three systems (viz. YBCO-123, Bi2212, Bi-2223) perhaps due to the difference in $c$ parameter. Moreover, in $\mathrm{Bi}-2223$, a high pressure of pelletization at $800 \mathrm{MPa}$ also causes inhibition of intergrowth of $\mathrm{Ca}-$ $\mathrm{Cu}-\mathrm{O}$ admixed phase to the matrix of Bi-2212. Fradina et

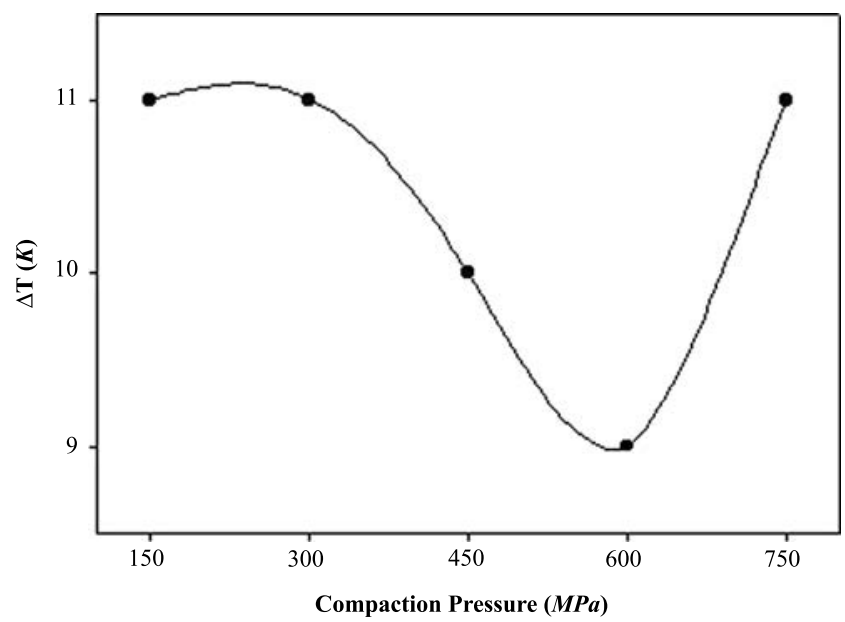

Fig. 2 Transition width for System I

Table 1 The critical temperature $T_{\mathrm{c} \text {,zero }}(\mathrm{K}), T_{\mathrm{c} \text {,onset }}(\mathrm{K}), \Delta T_{\mathrm{c}}(\mathrm{K})$ and mass density of the samples for System I

\begin{tabular}{llllll}
\hline Sample & Pressure $(\mathrm{MPa})$ & $T_{\mathrm{c}}($ onset $) \mathrm{K}$ & $T_{\mathrm{c}}(R=0) \mathrm{K}$ & $\Delta T_{\mathrm{c}} \mathrm{K}$ & $\mathrm{Mass}$ density $\left(\mathrm{g} / \mathrm{cm}^{3}\right)$ \\
\hline A & 150 & 120 & 109 & 11 & 5.0725 \\
B & 300 & 121 & 110 & 11 & 5.1675 \\
C & 450 & 124 & 114 & 10 & 5.2682 \\
D & 600 & 124 & 115 & 9 & 5.2232 \\
E & 750 & 120 & 109 & 11 & 5.1415 \\
\hline
\end{tabular}



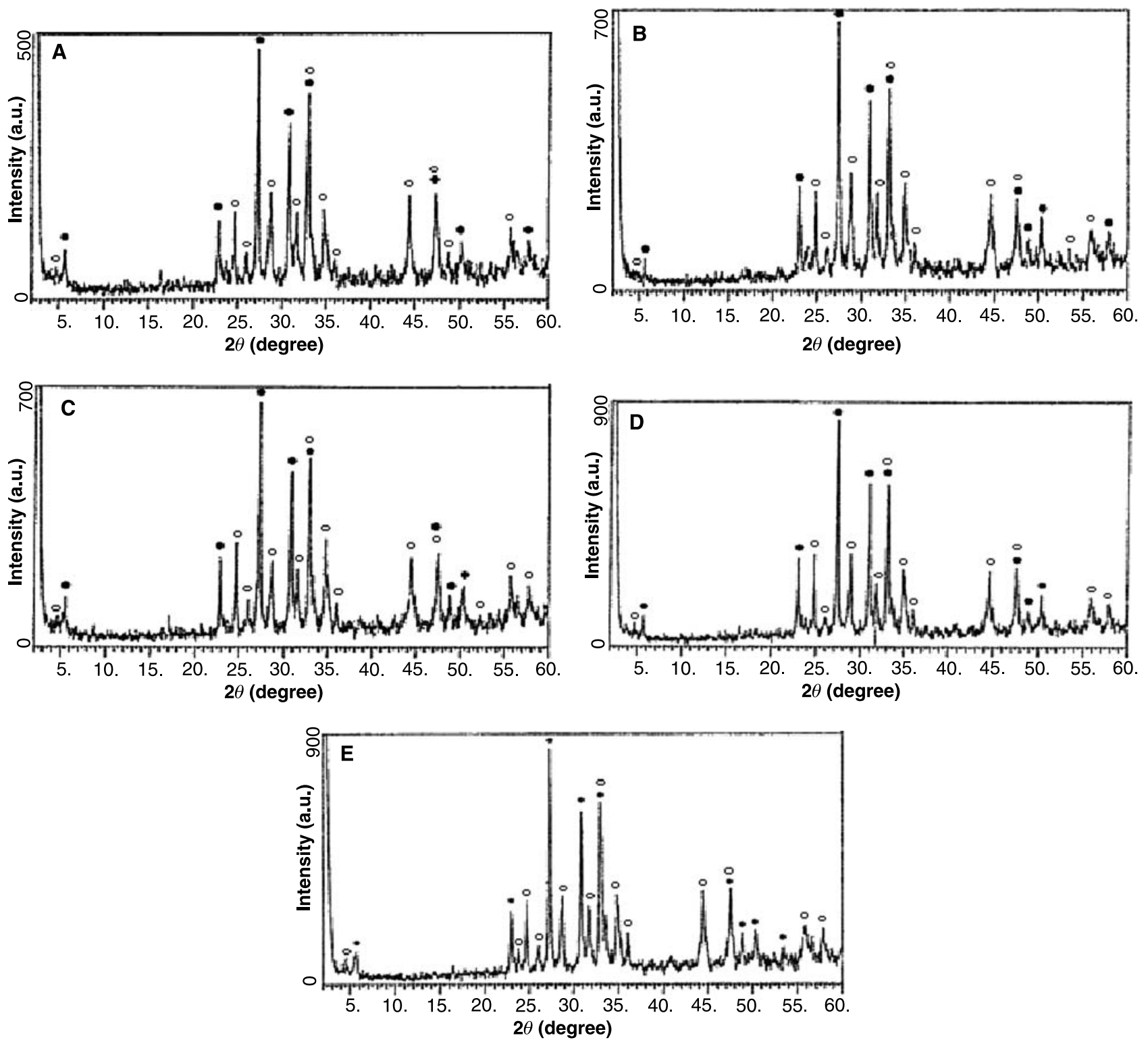

Fig. 3 XRD patterns of System I, A (150 MPa), B (300 MPa), C (450 MPa), D (600 MPa), and E (750 MPa). ॰-High $T_{\mathrm{c}}$ phase, $\bullet-L o w ~ T_{\mathrm{c}}$ phase

al. [3] found that the pressure of pelletization of samples in the 100-500 MPa interval does not influence the speed of formation of 2223 phase. The quality of grain contacts in samples pelletized at pressures 100, 200, $300 \mathrm{MPa}$ is rather bad, probably because of a non-uniform diffusion of atoms. The necessity of the application of compaction pressures in the 400-500 $\mathrm{MPa}$ range is stated in the literature for the preparation of bismuth superconducting ceramics in the $\mathrm{Bi}_{1.7} \mathrm{~Pb}_{0.3} \mathrm{Sr}_{2} \mathrm{Ca}_{2.5} \mathrm{Cu}_{3.5} \mathrm{O}_{10-\delta}$ composition. The superior properties of the pellets compacted in the 450-600 MPa range in this work is in agreement with the previous results given in the literature.

The powder XRD patterns of all samples are given in Fig. 3. The high- $T_{\mathrm{c}}$ and the low- $T_{\mathrm{c}}$ phase peaks were iden- tified using the tables given by Bansal et al. and Pandey et al. [11, 12]. All samples have multiphase nature with highand low- $T_{\mathrm{c}}$ peaks along with $\mathrm{CuO}$ identified at $2 \theta=38.8^{\circ}$ as an impurity phase, which also indicates the difficulty in obtaining a single-phase material by the conventional ceramic method. The characteristic $H(002)$ and $L(002)$ peaks were observed at $2 \theta=4.7^{\circ}$ and $2 \theta=5.7^{\circ}$, respectively, for all samples with different intensities. The intensities of the most visible peaks in the $2 \theta=20^{\circ}-25^{\circ}$ range were $L(008)$ at $2 \theta=23.05^{\circ}$ and $H(113)$ increased with compaction pressure of up to $450 \mathrm{MPa}$ (sample C). The intensity of $L(115)$ peak decreased slightly for samples $\mathrm{C}$ and $\mathrm{D}$. The intensity of $L(117)$ peak at $2 \theta=31^{\circ}$ remained lower than the intensity of $L(200)+H(200)$ at $2 \theta=33.125^{\circ}$ for all samples. 
Table 2 Determined unit cell parameters for tetragonal 2223 phase for System I

\begin{tabular}{llll}
\hline$a=b(\AA)$ & $c(\AA)$ & $V\left(\AA^{3}\right)$ & $\alpha=\beta=\gamma\left({ }^{\circ}\right)$ \\
\hline 5.3006 & 36.3240 & 1020.580 & 90 \\
5.3027 & 36.3285 & 1021.519 & 90 \\
5.3275 & 36.5772 & 1038.179 & 90 \\
5.3433 & 36.3573 & 1038.057 & 90 \\
5.3493 & 35.9554 & 1028.873 & 90 \\
\hline
\end{tabular}

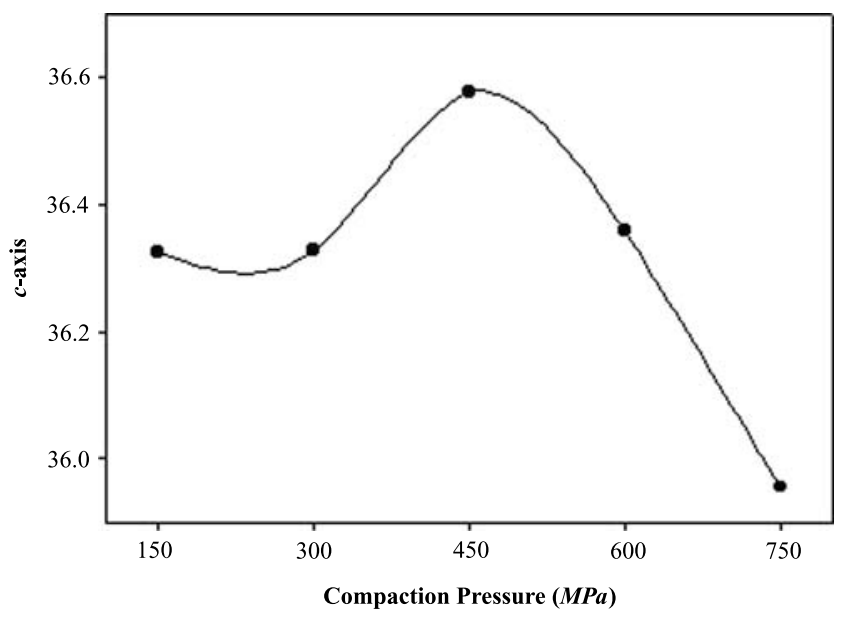

Fig. 4 Variation of $c$-axis as a function of applied pressure

Another clear observation was found for the peak corresponding to $2 \theta=34.50^{\circ}$, which was labeled as $H(204)$. The presence of the variation of the intensity of the $H$ (204) peak located at $2 \theta=34.50^{\circ}$ with compaction pressure, where an increase of up to $450 \mathrm{MPa}$ (sample C) and then a decrease with increasing pressure was another important finding of the XRD characterizations.

It can be seen from XRD patterns that with increasing compaction pressure up to an optimum value, the intensities of the peaks corresponding to high- $T_{\mathrm{c}}$ phase increase while those reflections corresponding to the low- $T_{\mathrm{c}}$ phase decrease. In this study, X-ray powder diffraction data was used for structural refinements. Correlations were examined between superconducting transition temperatures and microstructural parameters of the phases.

The lattice parameters, unit cell structures and volumes for 2223 phase were determined by using WATFOR-TT program and are given in Table 2. The 2223 high- $T_{\mathrm{c}}$ phase is tetragonal. The presence of such tetragonal unit cell structures in $\mathrm{Pb}$-doped Bi-based superconductors have been reported also by other groups [13].

About 20 lines were taken into account for the phase identification of all the samples. The values of the lattice parameters obtained for sample D and especially for sample $\mathrm{C}$ are similar to theoretical values [14]. Variation of c-axis parameter with applied pressure is shown in Fig. 4.
Quidwal et al. [15] also have found that the synthesized $\mathrm{Bi}_{1.6} \mathrm{~Pb}_{0.4} \mathrm{Sr}_{2} \mathrm{Ca}_{2} \mathrm{Cu}_{3} \mathrm{O}_{y}$ was a multiphase system. The system had 2223 and 2212 as the dominating phases which were both determined to be tetragonal. Patterns obtained from XRD measurements provide knowledge not only on superconducting phases but also on undesired impurity phases. It is well established that for an optimum hole concentration, $T_{\mathrm{c}}$ has a maximum value and above and below this optimum, $T_{\mathrm{c}}$ decreases. The hole concentration increase might be responsible for the improvement in the superconducting properties.

SEM studies have been carried out in order to observe the effect of compaction pressure on the orientation of the grains in the microstructure. The microstructures of the top surfaces of all System I pellets are given in the SEM microphotographs in Fig. 5 at a similar $2 \mathrm{~K} \times$ magnification. In all samples, the dominant structure is plate-like grains randomly distributed due to the presence of the pores between the grains. Microphotographs for $300 \mathrm{MPa}$ (sample B) to $600 \mathrm{MPa}$ (sample D) pelletization reveal the clear orientation of the grains mostly in the plane of the figure, while sample A shows the grain orientation in all directions. This is a direct observation of texturing with increasing compaction pressure. Fine particles were visible on the top surface of pellet $\mathrm{E}$, which may have resulted from the fragmentation of grains at a high degree of deformation occurring at a high pressure of $750 \mathrm{MPa}$. It is also evident from the microphotographs that grains in the $450 \mathrm{MPa}$ pellet were bigger compared to the $300 \mathrm{MPa}$ pellet. In the $450 \mathrm{MPa}$ and $600 \mathrm{MPa}$ pellets even bigger grains which must have grown at the expense of the smaller grains were also visible. We attribute these occurrences to the effect of compaction on sample.

A plate-like nature is typical of the superconducting phase [16]. In conclusion, samples A and B had a fine and homogeneous microstructure with needle-like and rod-like grains, which may be more preferable for superconducting properties. This behavior is attributed to the increasing connectivity between the superconducting grains. In sample $\mathrm{E}$ we can see the deformation in crystal structure. It can be concluded that these morphological observations for samples $\mathrm{C}$ and $\mathrm{D}$ with a coarser grain structure support the previous findings about these samples having the highest offset temperatures. 
Fig. 5 Scanning electron microscope photographs of the top surfaces of System I, A (150 MPa), B (300 MPa), C (450 MPa), D (600 MPa), and $\mathbf{E}(750 \mathrm{MPa})$

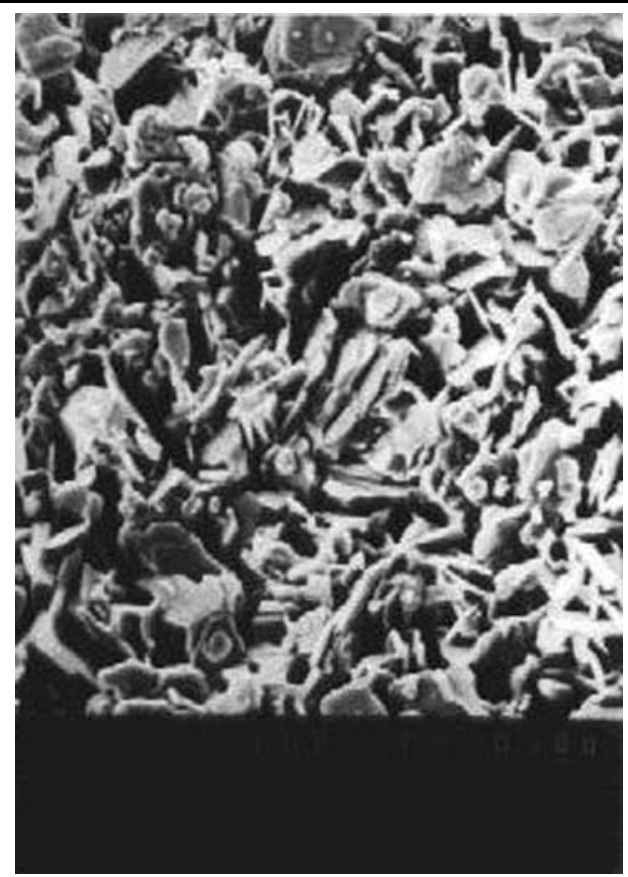

(A)

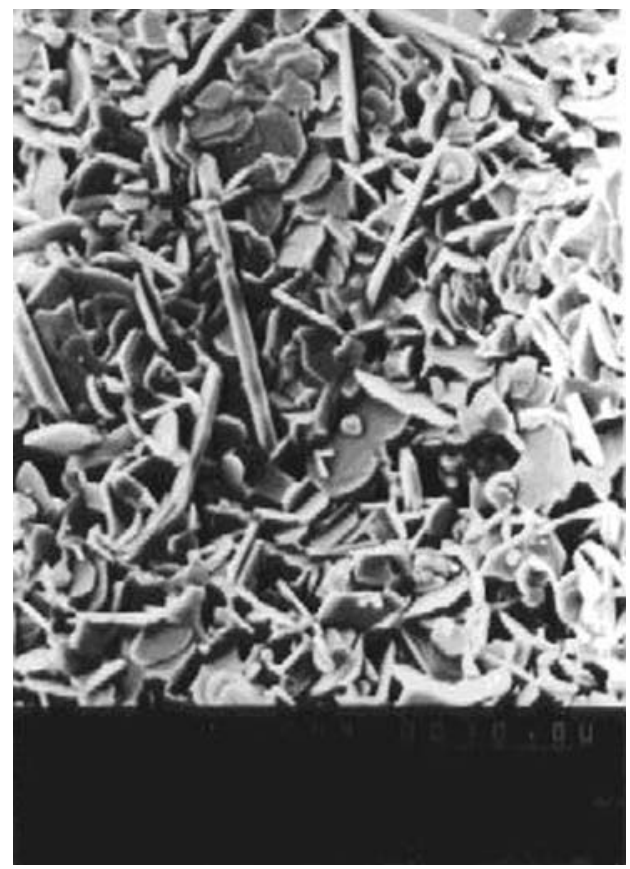

(C)

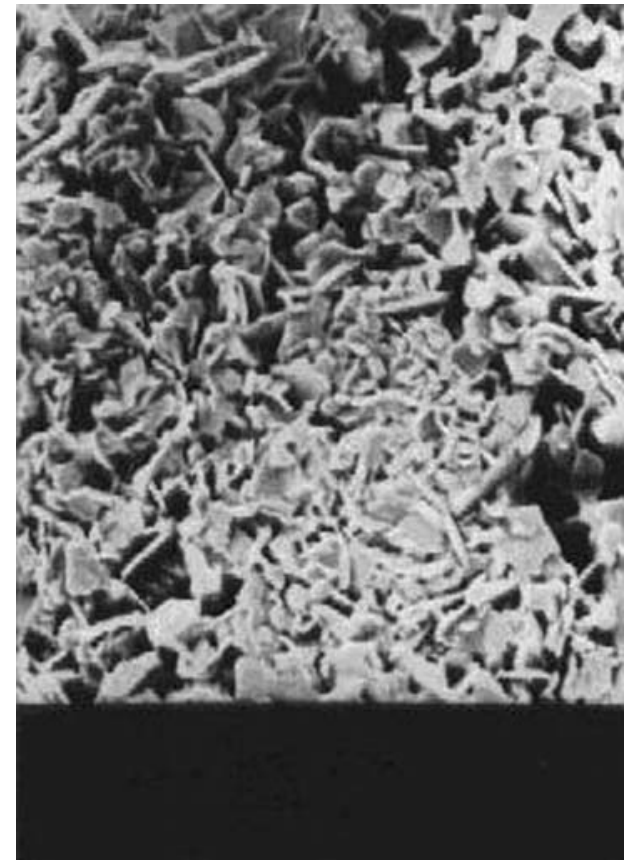

(B)

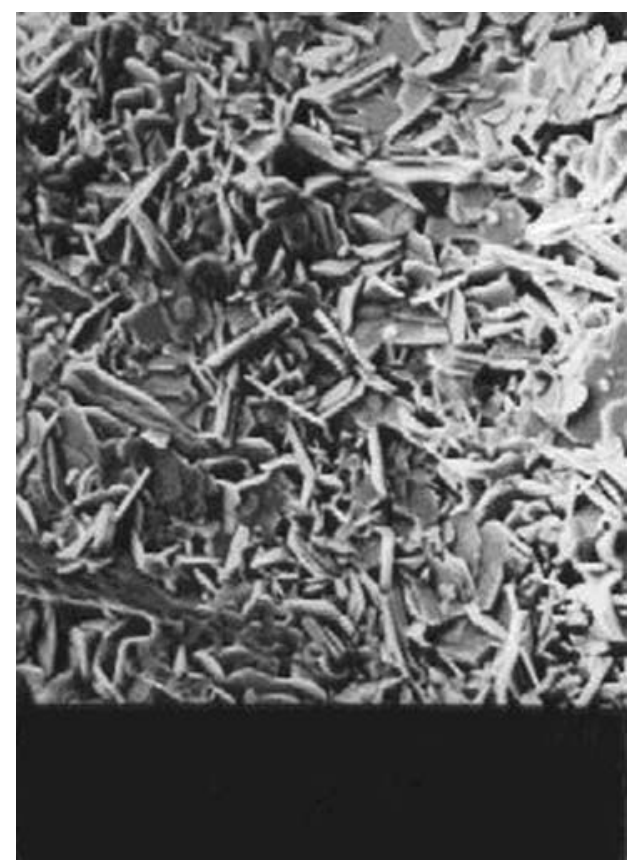

(D)
The theoretical density of BPSCCO system is about $6.3 \mathrm{~g} / \mathrm{cm}^{3}$ obtained from the lattice parameters [17]. The density of the pellets prepared in this work were determined to be $5.0725 \mathrm{~g} / \mathrm{cm}^{3} ; 5.1675 \mathrm{~g} / \mathrm{cm}^{3} ; 5.2682 \mathrm{~g} / \mathrm{cm}^{3}$; $5.2232 \mathrm{~g} / \mathrm{cm}^{3} ; 5.1415 \mathrm{~g} / \mathrm{cm}^{3}$ from A to E, respectively, by Archimedes water displacement method using the following formula:

$$
\rho=\frac{W(a) \rho(f l)}{W(a)-W(f l)}
$$

where, $\rho(f l)$ is the density of the liquid, $W(a)$ is the weight of the solid in air and $W(f l)$ is the weight of the solid in liquid and is further shown in Fig. 6.

Most open pore volume was intruded by water during 
Fig. 5 (Continued)

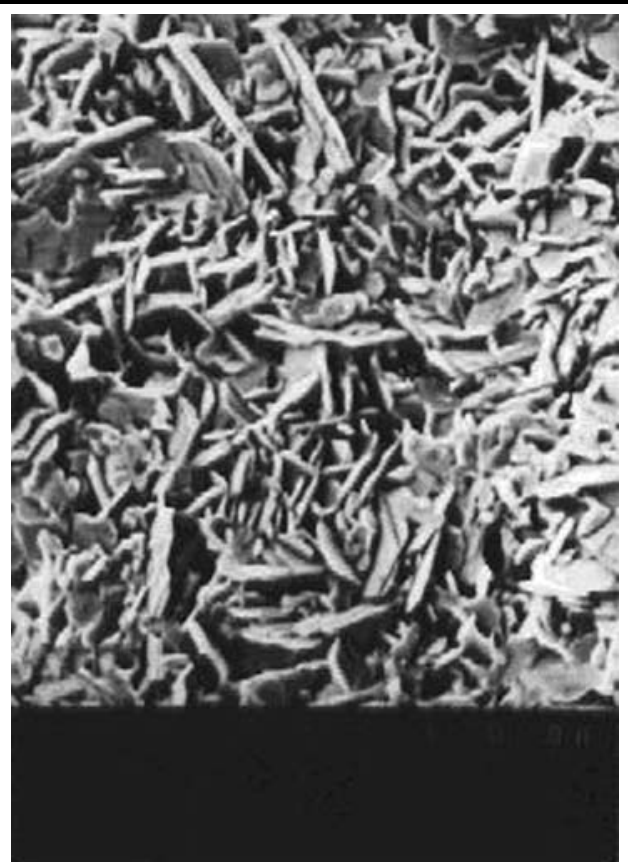

(E)

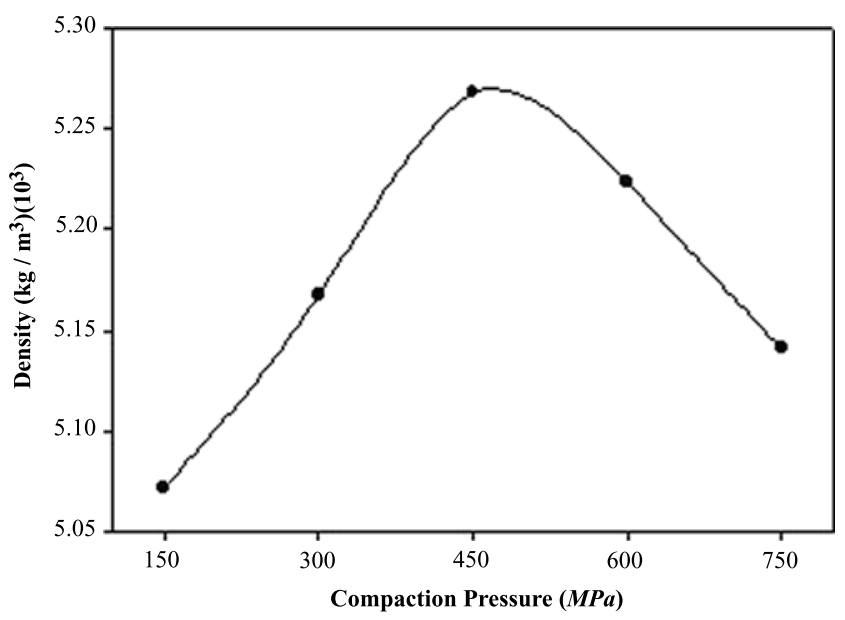

Fig. 6 Measured density values versus pressure

these tests [18]. The densities of the same pellets were estimated to be in the $2.8-3.5 \mathrm{~g} / \mathrm{cm}^{3}$ range from their dimensional measurements. The bulk densities evaluated by water displacement method were in the $80-84 \%$ range of theoretical density. The pellet densities became closer to the theoretical density with increasing compaction pressure. This is in agreement with the results obtained by Pintu Sen et al. [10], where with increasing compaction pressure pellets became more densified due to compaction causing less oxygen absorption.

\section{System II}

The temperature dependence of resistances for all samples is shown in Fig. 7 in the $95-185 \mathrm{~K}$ range. All samples dis-

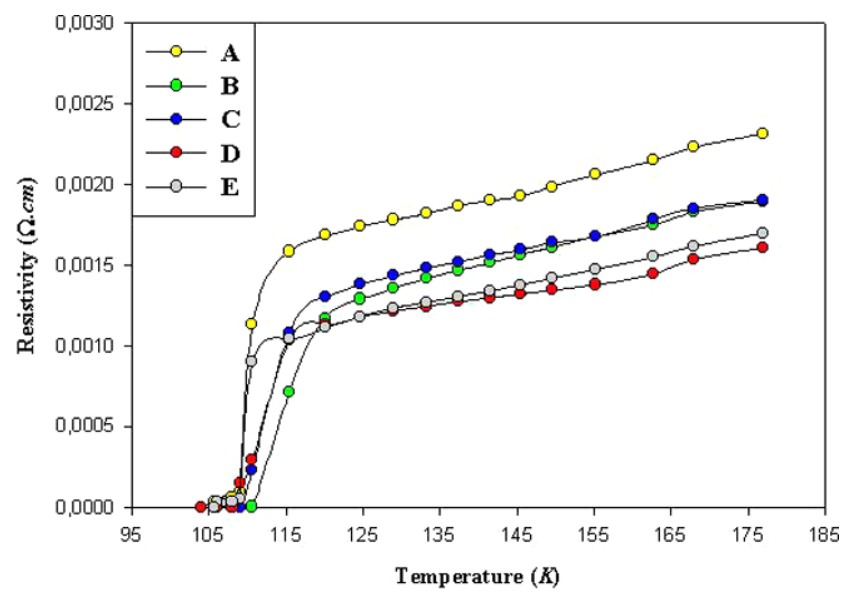

Fig. 7 Resistivity versus temperature for System II, A (150 MPa), $B$ (300 MPa), $C$ (450 MPa), D (600 MPa), E (750 MPa)

played a metallic character above the onset temperature. The onset temperatures of the samples were $117 \mathrm{~K}, 119 \mathrm{~K}$, $117 \mathrm{~K}, 117 \mathrm{~K}$ and $117 \mathrm{~K}$ respectively. The critical temperature, the zero resistance temperature, of samples from A to E were $104 \mathrm{~K}, 109 \mathrm{~K}, 108 \mathrm{~K}, 106 \mathrm{~K}$ and $104 \mathrm{~K}$, respectively, and are further tabulated in Table 3.

$\mathrm{Ag}$ is more reactive with the $(\mathrm{Bi}, \mathrm{Pb})_{2} \mathrm{Sr}_{2} \mathrm{Ca}_{n} \mathrm{Cu}_{n+1} \mathrm{O}_{6+2 n}$ compound than the other compounds only in atmospheres containing oxygen. The $T_{\mathrm{c}}$ and $J_{\mathrm{c}}$ of Ag-doped $(\mathrm{Bi}, \mathrm{Pb})_{2} \mathrm{Sr}_{2}$ $\mathrm{Ca}_{2} \mathrm{Cu}_{3} \mathrm{O}_{10}$ are both depressed because $\mathrm{Ag}$ reacts with this compound. However, by processing in low oxygen partial pressures Ag can be used without degradation of properties.

Dou et al. [19] reported that $\mathrm{Ag}$ additions strongly react with $\operatorname{Bi}(2223)$ and destabilize the superconducting 
Table 3 The critical temperature $T_{\mathrm{c}, \text { zero }}(\mathrm{K}), T_{\mathrm{c}, \text { onset }}(\mathrm{K}), \Delta T_{\mathrm{c}}(\mathrm{K})$ and mass density of the samples for System II

\begin{tabular}{llllll}
\hline Sample & Pressure $(\mathrm{MPa})$ & $T_{\mathrm{c}}$ (onset) $\mathrm{K}$ & $T_{\mathrm{c}}(R=0) \mathrm{K}$ & $\Delta T_{\mathrm{c}} \mathrm{K}$ & $\mathrm{Mass}$ density $\left(\mathrm{g} / \mathrm{cm}^{3}\right)$ \\
\hline A & 150 & 117 & 104 & 13 & 5.0716 \\
B & 300 & 119 & 109 & 10 & 5.2607 \\
C & 450 & 117 & 108 & 9 & 5.4284 \\
D & 600 & 117 & 106 & 11 & 5.4874 \\
E & 750 & 117 & 104 & 13 & 5.4018 \\
\hline
\end{tabular}

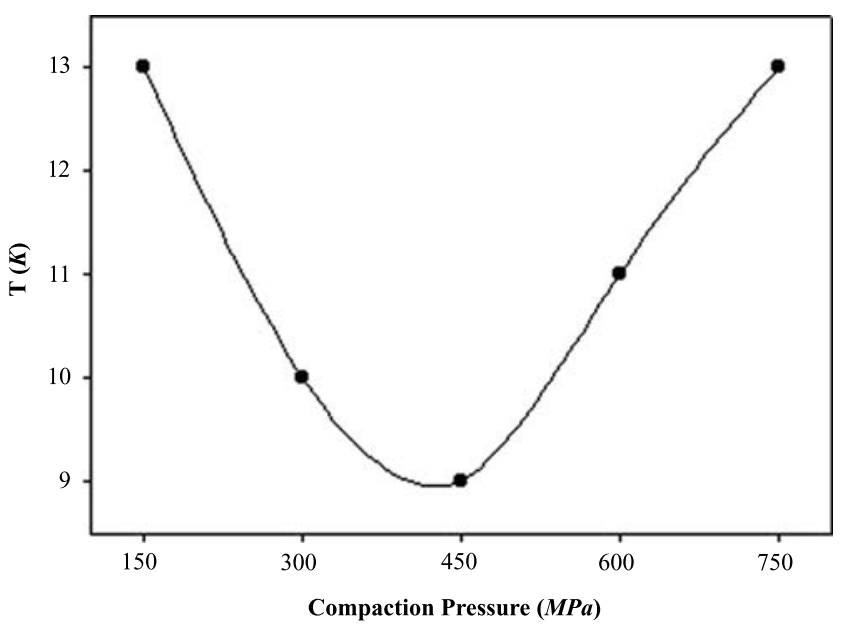

Fig. 8 Transition width for System II

phase, resulting in a depression of $T_{\mathrm{c}}$ and lattice parameters when samples were treated in air or pure oxygen. Contrary to previous researchers, Matsushita et al. [20] obtained the values of zero resistance higher than $110 \mathrm{~K}$ in $\mathrm{Bi}_{2-x} \mathrm{~Pb}_{x} \mathrm{Sr}_{2} \mathrm{Ca}_{2} \mathrm{Cu}_{3} \mathrm{O}_{y}+\mathrm{Ag}(40-60 \mathrm{wt} \%$ ) compositions.

The highest values of the offset temperature are for samples $\mathrm{B}$ and $\mathrm{C}$. The transition width was $13 \mathrm{~K}, 10 \mathrm{~K}, 9 \mathrm{~K}$, $11 \mathrm{~K}$ and $13 \mathrm{~K}$, respectively, from sample A to E, which indicated the presence of highly pure phase structure as shown in Fig. 8. Khan et al. [21] reported $T_{\mathrm{c}}$ as $106 \mathrm{~K}$ for Ag-doped samples, which was close to the findings of this work.

$\mathrm{Pb}$-doped BSCCO (2223) system has $110 \mathrm{~K}$ offset temperature. Results obtained from four-point probe measurements were close to this value. Rojek et al. [22] reported $T_{\mathrm{c}}$ onsets of about $119 \mp 1 \mathrm{~K}$ in pellets with $\mathrm{Bi}_{1.4} \mathrm{~Pb}_{0.6} \mathrm{Ag}_{0.2} \mathrm{Sr}_{2} \mathrm{Ca}_{2} \mathrm{Cu}_{3} \mathrm{O}_{10-x}$ composition, which were prepared by the solid-state reaction method. These results are in agreement with the above-mentioned results of this work.

In conclusion, substitution of $\mathrm{Bi}$ by $\mathrm{Ag}$ in that ratio slightly depresses the formation of high- $T_{\mathrm{c}}$ phase. It may be possible to state that the optimum compaction pressure for Ag-substituted BSCCO system is in the $300-450 \mathrm{MPa}$ range.

The powder XRD patterns of all samples are given in Fig. 9. Using the tables given by Bansal et al. and Pandey et al. $[11,12]$, the high- $T_{\mathrm{c}}$ and low- $T_{\mathrm{c}}$ phase peaks were identified. All samples had a multiphase nature with highand low- $T_{\mathrm{c}}$ phase peaks. Impurity phase $\mathrm{CuO}$ is observed at $2 \theta=38.8^{\circ}$ in samples A, D and $\mathrm{E}$. The characteristic peaks of BSCCO system, $L(002)$ and $H(002)$, are not visible in all samples. The most visible peaks, which can be seen in the $2 \theta=25^{\circ}-30^{\circ}$ range were $L(115)$ at $2 \theta=27.6^{\circ}$ and $H(117)$ at $2 \theta=29.02^{\circ}$. Intensity of $H(117)$ peak reaches to its maximum value in sample B. The intensity of $H(111)$ peak at $2 \theta=23.17^{\circ}$ increases while the intensity of $L(113)$ peak at $2 \theta=24.97^{\circ}$ decreases to the compaction pressure of $450 \mathrm{MPa}$. The intensity of $H(2012)$ peak at $2 \theta=44.77^{\circ}$ and the $H(0020)$ peak at $2 \theta=49.17^{\circ}$ reach their maximum value for sample B. In spite of the multiphase nature of the samples, the dominant phase was high- $T_{\mathrm{c}}$ phase. Since the quantity of $\mathrm{Ag}$ added was very small, the possibility of its detection, if involved in any compound-formation in XRD spectra is negligible, and consequently no such lines could be identified in the spectra.

In phase identification about 21 lines were taken into account for all samples. Calculated unit cell parameters for 2223 phase are given in Table 4. The unit cell parameters determined for samples $\mathrm{B}$ and $\mathrm{C}$ were closer to the theoretical values. This system has a tetragonal unit cell with lattice parameters of $a \approx b \approx 5.3 \AA$ and $c \approx 36 \AA$. Deviations of these values from the ideal structure values reported in the literature suggest the possible formation of a distorted crystal structure. Such deviations were encountered in both systems and this can be due to the presence of different cation ratios and varying oxygen contents. Mishra et al. [23] have reported $T_{\mathrm{c}}=102 \mathrm{~K}$ and $c \approx 36.47 \AA$ for pure $\mathrm{BPbSCCO}$ with a nominal composition of $\mathrm{Bi}_{1.6} \mathrm{~Pb}_{0.4} \mathrm{Sr}_{2} \mathrm{Ca}_{2} \mathrm{Cu}_{3} \mathrm{O}_{\delta}$. They determined $T_{\mathrm{c}} \approx$ $98 \mathrm{~K}$ and $c \approx 36.56 \AA$ by the substitution of $\mathrm{Nb}$ for $\mathrm{Bi}$ $\left(\mathrm{Bi}_{1.5} \mathrm{Nb}_{0.1} \mathrm{~Pb}_{0.4} \mathrm{Sr}_{2} \mathrm{Ca}_{2} \mathrm{Cu}_{3} \mathrm{O}_{\delta}\right)$, which are in accordance with our results. The increase in the $c$-axis is directly related with increasing $T_{\mathrm{c}}$. Variation of $c$-axis with applied pressure is shown in Fig. 10. Unit cell parameters which were determined from XRD data and the resistivity measurements are in good agreement.

Khan et al. [21] reported that with the addition of $\mathrm{Ag}$ $(x=0.005)$, only those peaks corresponding to low- $T_{\mathrm{c}}$ phase were observed. It is known that the volume fraction of 


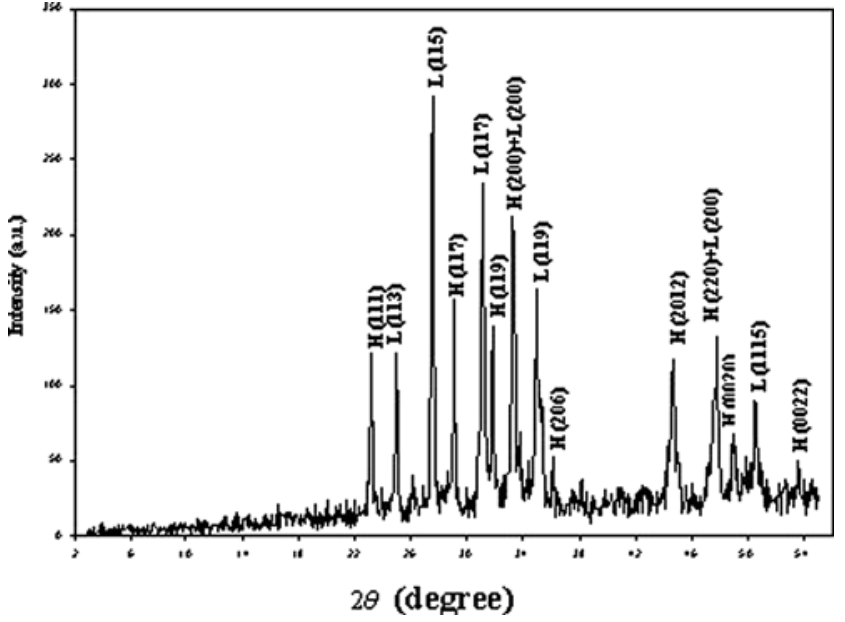

(A)

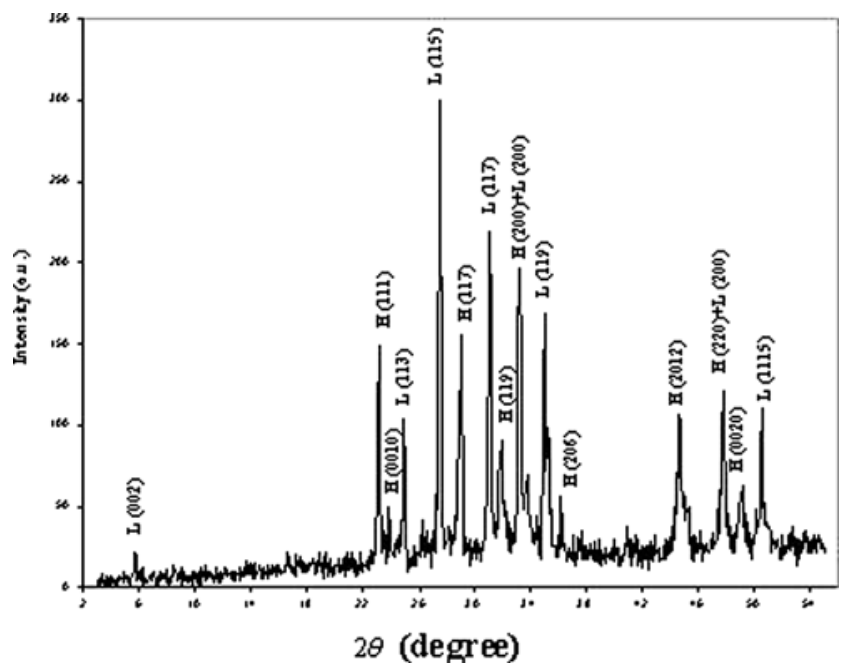

(C)

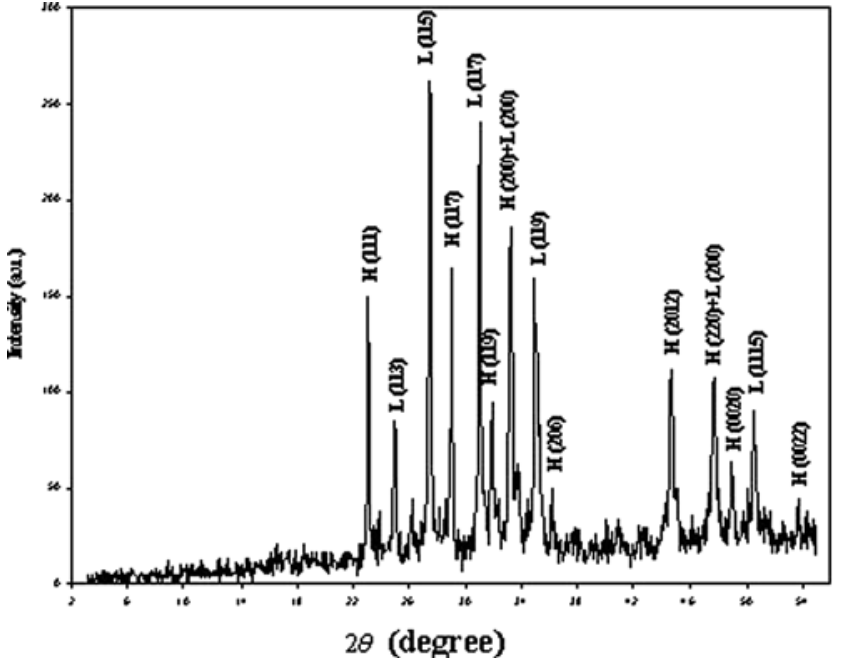

(B)

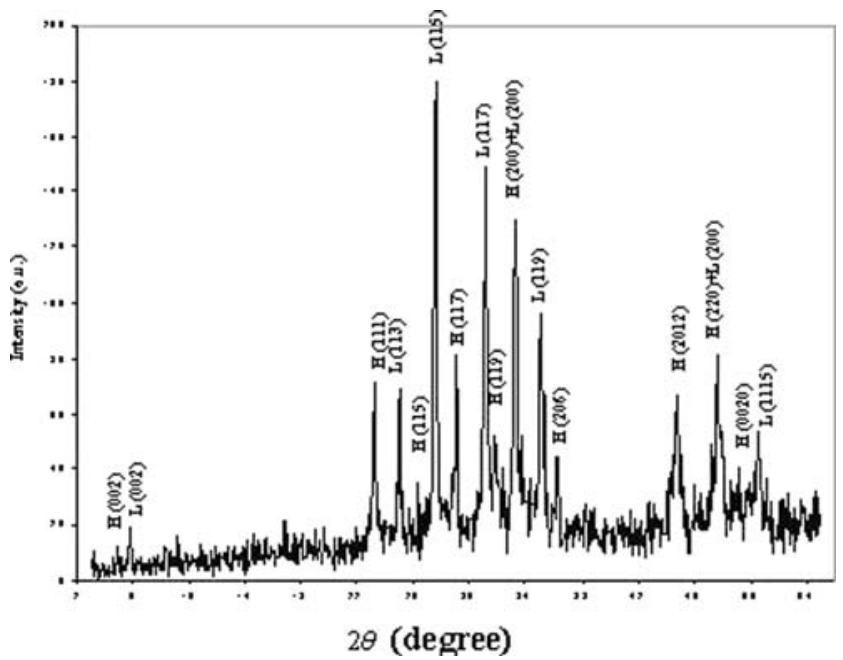

(D)

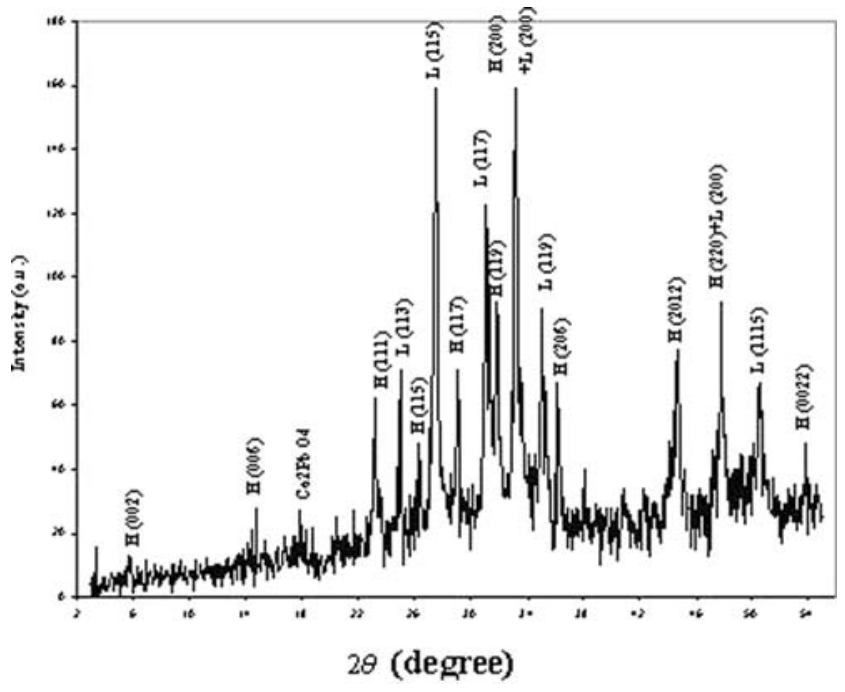

(E)

Fig. 9 XRD patterns of System II, A (150 MPa), B (300 MPa), C (450 MPa) and D (600 MPa), E (750 MPa) 


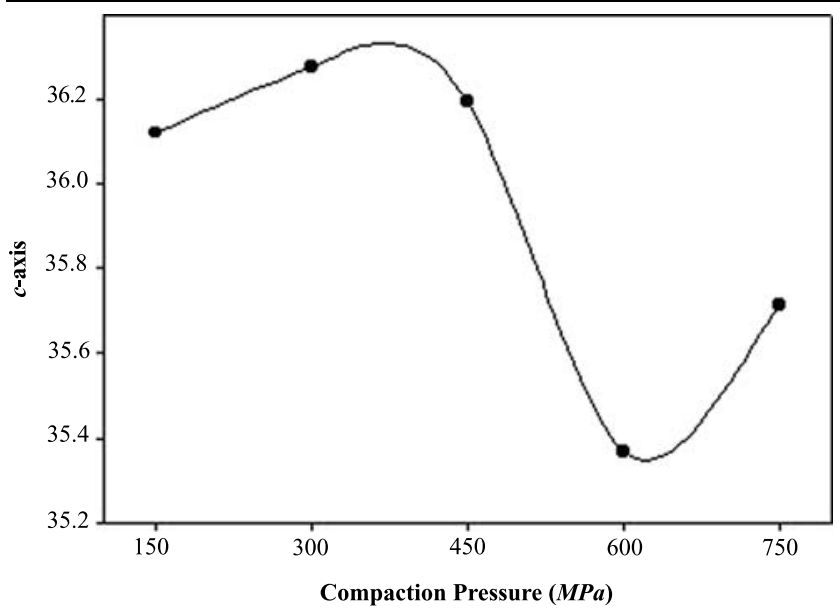

Fig. 10 Variation of $c$-axis as a function of applied pressure

the high- $T_{\mathrm{c}}$ phase increases with increase in sintering time, while the low- $T_{\mathrm{c}}$ phase decreases. Higher sintering time in the present study could be the reason for the higher content of the high- $T_{\mathrm{c}}$ phase.

The microstructures of top surfaces of all pellets are shown in Fig. 11. SEM microphotographs are taken at $2500 \times$ magnification for all samples. Sample A has homogeneous structure in plate-like and needle-like forms. With increasing compaction pressure, plate-like form became more evident. The grain size is increasing also with applied pressure and highest grain size can be seen in sample C. Higher grain size provides stronger contact between grains, which leads to the improvement of high- $T_{\mathrm{c}}$ phase properties. These observations are in accordance with the results obtained from resistivity measurements and XRD.

The densities of samples were determined by Archimedes water displacement method. By using this method, obtained densities of pellets were $5.0716 \mathrm{~g} / \mathrm{cm}^{3}$ for sample A, $5.2607 \mathrm{~g} / \mathrm{cm}^{3}$ for sample B, $5.4284 \mathrm{~g} / \mathrm{cm}^{3}$ for sample C, $5.4874 \mathrm{~g} / \mathrm{cm}^{3}$ for sample D and $5.4018 \mathrm{~g} / \mathrm{cm}^{3}$ for sample E, and are shown in Fig. 12. Densities obtained by water displacement technique were in the $80-87 \%$ range of theoretical density calculated from the lattice parameters to be $6.3 \mathrm{~g} / \mathrm{cm}^{3}$. The densities of pellets were calculated to be in the $3.78-4.50 \mathrm{~g} / \mathrm{cm}^{3}$ range from dimensional measurements. If theoretical density is assumed to be equal to $6.3 \mathrm{~g} / \mathrm{cm}^{3}$, this indicates that the pellets do have $29-40 \%$ porosity. It was reported that addition of $20-30 \%$ Ag increases the material density, improves the grain boundaries and increases pinning strength [24].

\section{Conclusion}

The effect of compaction pressure on the superconducting and structural properties of BPSCCO ceramic superconductors was studied in this work. The main goal of the study was the determination of an optimum compaction pressure for ceramic pellet formation prior to sintering since there is no consensus on the level of the necessary compaction pressure in the literature. We have examined the effect of compaction pressure for both undoped (System I) and doped (System II) systems in order to determine the optimum compaction pressure for BPSCCO ceramic superconductors.

Samples prepared by applying five different compaction pressures have been characterized by resistivity-temperature determinations, X-ray diffraction, scanning electron microscope photographs and density measurements carried out by Archimedes water displacement method. Additional data about properties of the systems were obtained by determining the unit cell parameters by using X-ray diffraction data. Results indicated that zero resistance-temperature and unit cell parameters were improved for both systems at the optimum compaction pressure. Comparison of the variation of resistance with temperature in these systems revealed that the resistivity values in the metallic character region remained almost unchanged, which is attributed to the small amount of substitution ratio. Transition width, a sign of the purity of the system, was lower for System I. The densities which were considered to be a measure of the degree of compaction were closer to the theoretical values for samples C (450 MPa) and D (600 MPa) in both systems. Smaller density indicates the presence of pores between grains in the structure which affects $T_{\mathrm{c}}$ values negatively. Application of lower compaction pressures than necessary for the formation of Bi-2223 single phase may cause a decrease in the contact area among the superconducting grains and consequently a higher level of porosity may be generated. The results of this work indicate that the improvement in the superconducting properties and an increase in $T_{\mathrm{c}}$ is due to the increase in contact area among the superconducting grains.

Comparison of SEM microphotographs shows that in both systems plate-like grain alignment is dominant. However, for System I higher grain sizes provide stronger contacts which improve superconducting properties. In both systems, sample $\mathrm{C}$ has the highest grain sizes. The density values for all samples are almost the same and are less than the theoretical density value of $6.3 \mathrm{~g} / \mathrm{cm}^{3}$ for BSCCO ceramic superconductors. Smaller density values are an indication of looser structures and pores between grains. The unit cell parameters obtained from diffraction patterns were closer to the theoretical values for sample $\mathrm{C}$ in both systems. Comparison of the results obtained from resistivity-temperature determination, XRD analysis, SEM microphotographs and calculated unit cell parameters indicated that the structural and superconducting properties were improved for sample C (450 MPa) in both systems.

System I had improved superconducting properties than System II. This may be explained by the substitution of $\mathrm{Bi}^{3+}$ by $\mathrm{Ag}^{1+}$ in System II. The substituted element $\mathrm{Ag}^{1+}$ is $1 \mathrm{~B}$ 
Fig. 11 Scanning electron microscope photographs of the top surfaces of System II, A (150 MPa), B (300 MPa), C (450 MPa), D (600 MPa), E (750 MPa)

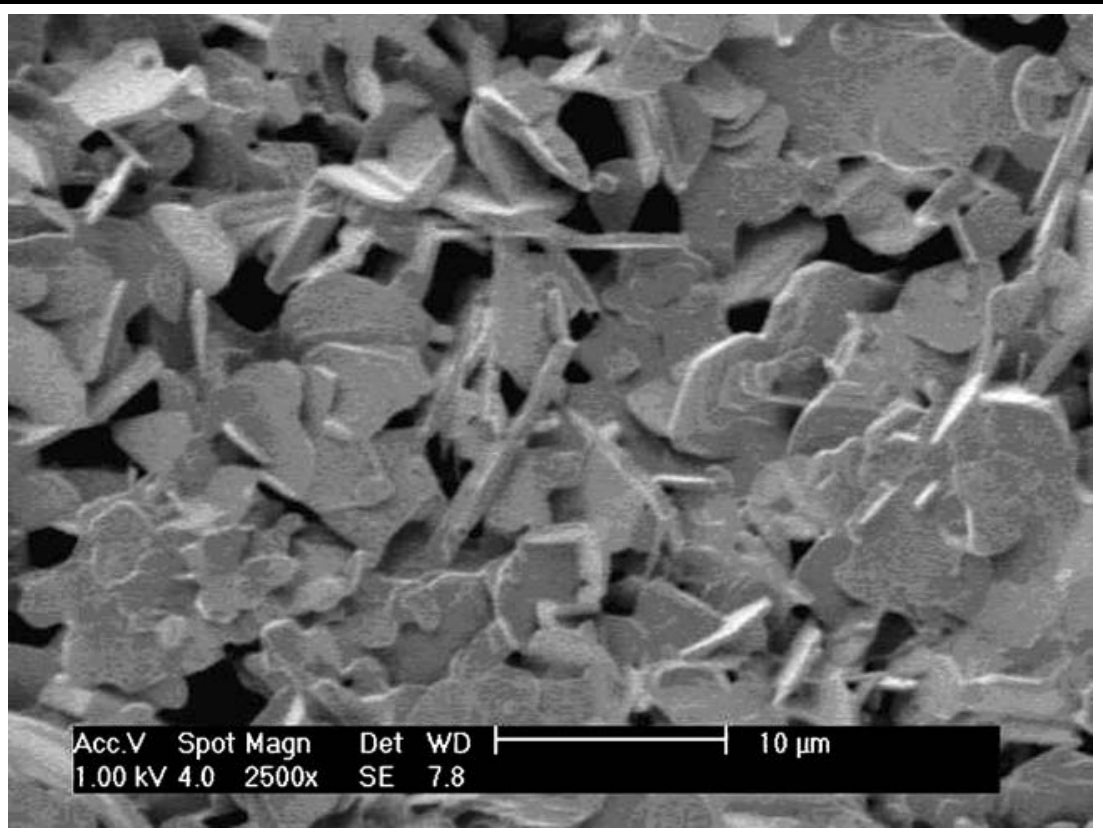

(A)

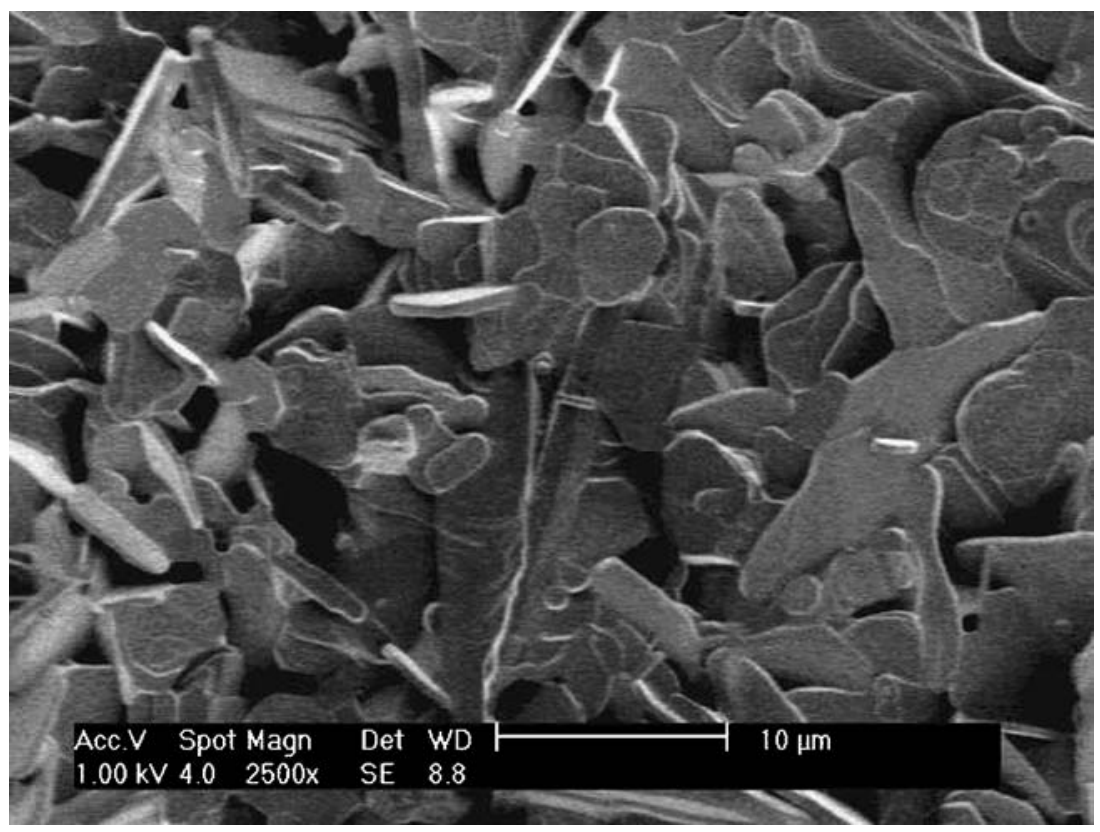

(B) group transition element with $1.26 \AA$ ionic radii which is higher than $0.96 \AA$ for $\mathrm{Bi}^{3+}$ which belongs to group 5A. It might be expected that partial substitution of an element with bigger ionic radii for an element with a smaller ionic radii may cause higher zero resistance values, but in this case it is more complicated. In the Bi-2223 system, the extra oxygen atoms are located in the double $\mathrm{Bi}-\mathrm{O}$ layers to stabilize the crystal structure of the system. As a result, some positive charges are localized in the so-called "charge reservoir." Reducing these extra oxygen atoms in the double $\mathrm{Bi}-\mathrm{O}$ layers will lead to the positive charges being released and transfer to the conduction layers ( $\mathrm{Cu}-\mathrm{O}$ planes). As more oxygen atoms are removed from the double $\mathrm{Bi}-\mathrm{O}$ layers (this means less oxygen nonstoichiometry in $\mathrm{Bi}-2223$ ), more positive charges will be transferred to the $\mathrm{Cu}-\mathrm{O}$ layer. As a result, the carrier concentration will increase. Because chargetransfer largely takes place at the structural transition, therefore the sharp increase of $n_{\mathrm{c}}$ occurs at about $T_{\mathrm{c}}$ instead of at room temperature. Namely, carrier concentration exhibits no changes at $300 \mathrm{~K}$ but changes significantly at $120 \mathrm{~K}$. Conse- 
Fig. 11 (Continued)

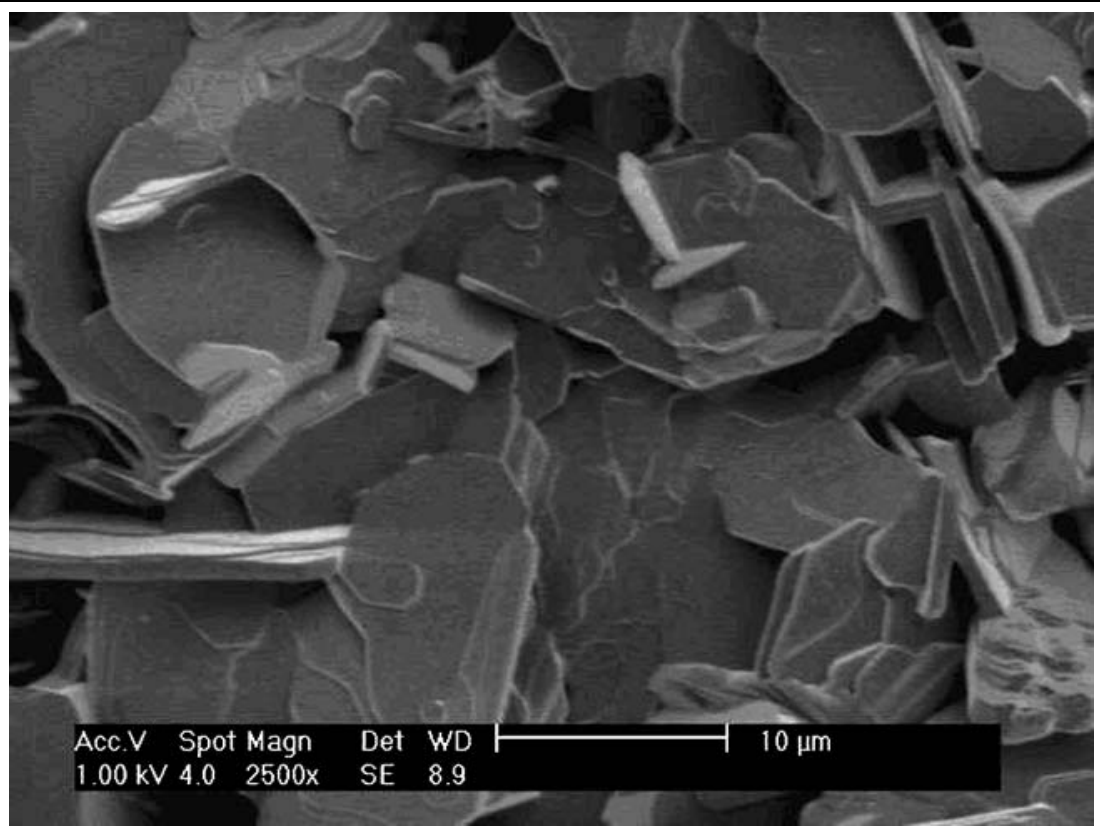

(C)

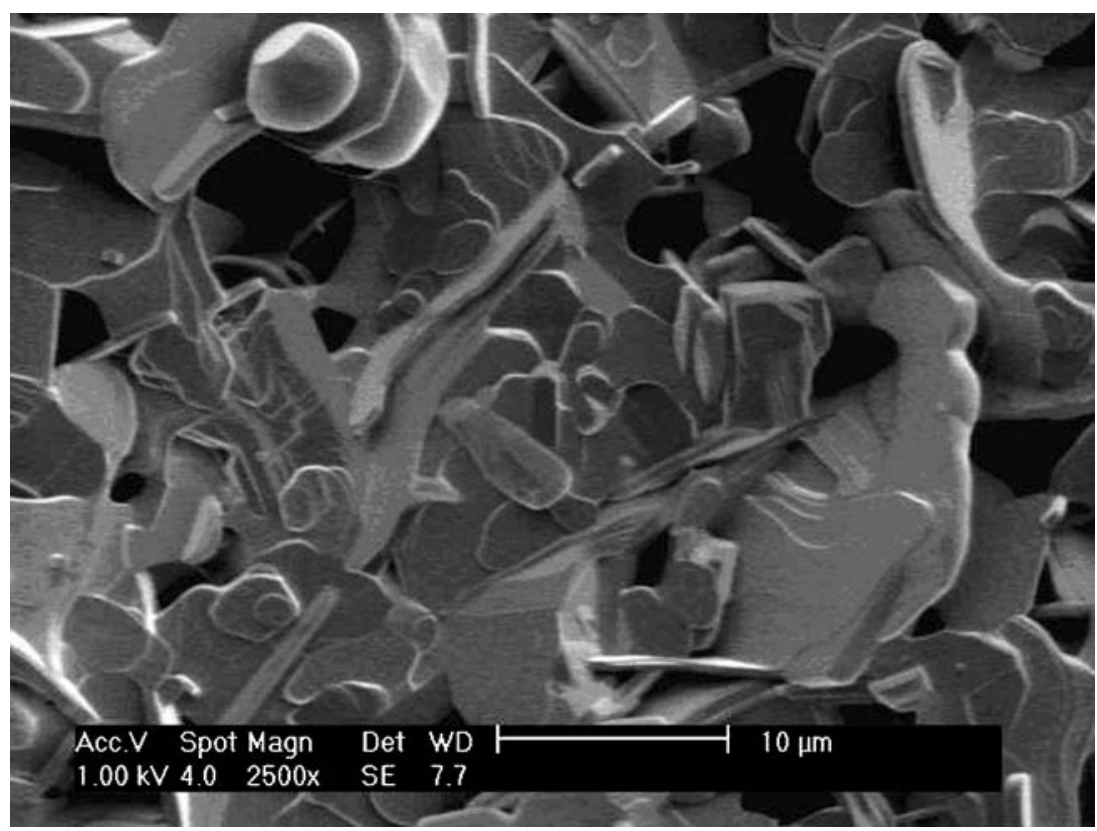

(D)

Table 4 Determined unit cell parameters for tetragonal 2223 phase for System II

\begin{tabular}{lllll}
\hline Pressure & $a=b(\AA)$ & $c(\AA)$ & $V\left(\AA^{3}\right)$ & $\alpha=\beta=\gamma\left({ }^{\circ}\right)$ \\
\hline $150 \mathrm{MPa}$ & 5.3004 & 36.1194 & 1014.773 & 90 \\
$300 \mathrm{MPa}$ & 5.2958 & 36.2746 & 1017.368 & 90 \\
$450 \mathrm{MPa}$ & 5.3046 & 36.1946 & 1018.487 & 90 \\
$600 \mathrm{MPa}$ & 5.3400 & 35.3659 & 1008.501 & 90 \\
$750 \mathrm{MPa}$ & 5.3261 & 35.7149 & 1013.164 & 90 \\
\hline
\end{tabular}

\footnotetext{
Springer
} 
Fig. 11 (Continued)

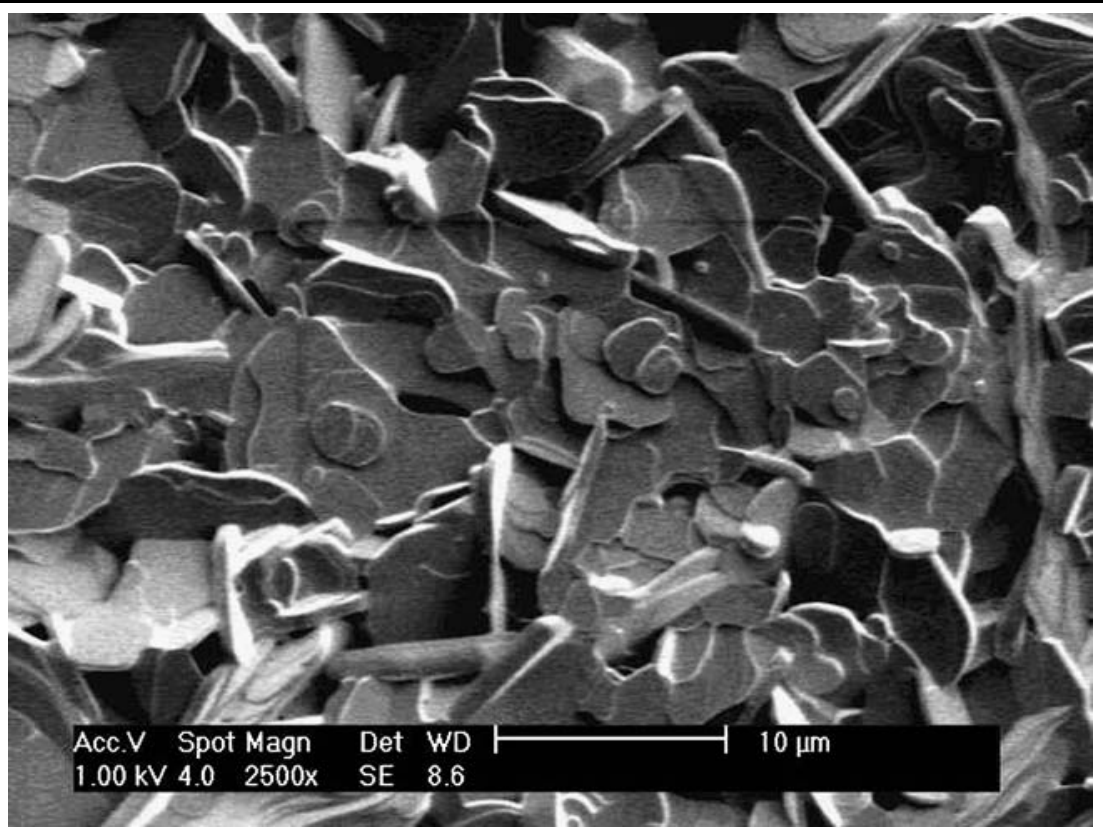

(E)

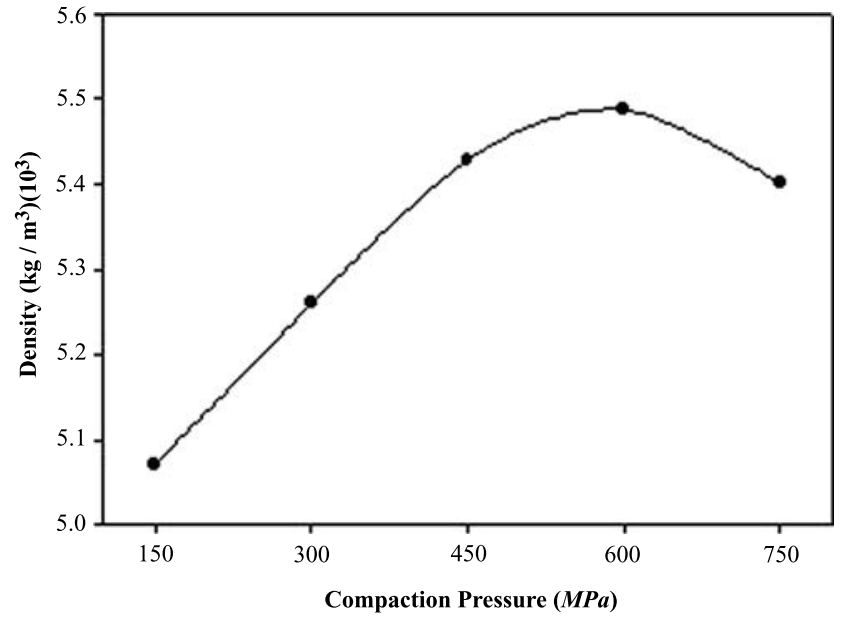

Fig. 12 Measured density values versus compaction pressure

quently, the increase of $n_{\mathrm{c}}$ enhances the $T_{\mathrm{c}}$. For that reason, decreasing amount of $\mathrm{Bi}_{2} \mathrm{O}_{3}$ powder in the compound will lead to a decrease in $T_{\mathrm{c}}$. Briefly, substitution site is as important as the ionic radii of the substituted element.

The superconducting properties of System I slightly differ from those of System II due to the amount of substitution. The experimental and theoretical analysis results of this study indicated that the optimum compaction pressure for BSCCO ceramic superconductors must be around $450 \mathrm{MPa}$.

\section{References}

1. Stassen, $\mathrm{S}$., et al.: Interdiffusion between $\mathrm{SrCuO}_{2}$ and a glassy precursor. Toward the understanding of the mechanism of formation of Bi based 2223 superconducting bulk ceramics. Physica C 270, 135-143 (1996)

2. Yau, J.K.F., et al.: The formation temperatures of $\mathrm{Bi}(\mathrm{Pb})-2223$ in partial vacuum. Physica C 339, 93-98 (2000)

3. Fradina, I.A., et al.: Influence of pelletization pressure on magnetic susceptibility samples of ceramics $\mathrm{Bi}_{2} \mathrm{Sr}_{2} \mathrm{CaCu}_{2} \mathrm{O}_{x}$. Physica C 311, 81-85 (1999)

4. Tepe, M., Avc1, I., Abukay, D.: Effect of pelletization pressure on structural properties and critical current hysteresis of ceramic superconducting $\mathrm{Bi}_{1.7} \mathrm{~Pb}_{0.3} \mathrm{Sr}_{2} \mathrm{Ca}_{2} \mathrm{Cu}_{3} \mathrm{O}_{y}$. Phys. Status Solidi (a) 198(2), 420-426 (2003)

5. Mune, P., Govea-Alcaide, E., Jardim, R.F.: Influence of the compacting pressure on the dependence of the critical current with magnetic field in polycrystalline $(\mathrm{Bi}-\mathrm{Pb})_{2} \mathrm{Sr}_{2} \mathrm{Ca}_{2} \mathrm{Cu}_{3} \mathrm{O}_{x}$ superconductors. Physica C 384, 491-500 (2003)

6. Govea-Alcaide, E., Garca-Fornaris, I., Mune, P., Jardim, R.F.: Improvement of the intergranular pinning energy in uniaxially compacting $(\mathrm{Bi}-\mathrm{Pb})_{2} \mathrm{Sr}_{2} \mathrm{Ca}_{2} \mathrm{Cu}_{3} \mathrm{O}$ ceramic samples. Eur. Phys. J. B 58, 373-378 (2007)

7. Topal, U.: Influence of pelletization pressure on the structural and transport properties of $\mathrm{TlCaBaCuO}$ superconductors. Phys. Status Solidi (a) 204(12), 4259-4265 (2007)

8. Bilgili, O., Selamet, Y., Kocabas, K.: Effects of Li substitution in Bi-2223 superconductors. J. Supercond. Nov. Magn. 21, 439-449 (2008)

9. Barat, P., et al.: Effect of pelletization pressure on texturing of a $\mathrm{YBa}_{2} \mathrm{Cu}_{3} \mathrm{O}_{7-\delta}$ sample. Physica C 218, 63-68 (1993)

10. Sen, P., et al.: The study of texturing of $\mathrm{Bi}_{2} \mathrm{Sr}_{2} \mathrm{CaCu}_{2} \mathrm{O}_{8+\delta}$ and $\mathrm{Bi}_{1.84} \mathrm{~Pb}_{0.34} \mathrm{Sr}_{1.91} \mathrm{Ca}_{2.03} \mathrm{Cu}_{3.06} \mathrm{O}_{10+\delta}$ superconductors as a function of pelletization pressure. Physica C 255, 306-310 (1995)

11. Bansal, S., et al.: $\mathrm{Pb}$-substituted $\mathrm{Bi}_{2} \mathrm{Sr}_{2} \mathrm{Ca}_{2} \mathrm{Cu}_{3} \mathrm{O}_{10}$ ceramics. Physica C 173, 260-266 (1991)

12. Pandey, D., et al.: Synthesis of $\mathrm{Bi}_{1.6} \mathrm{~Pb}_{0.4} \mathrm{Sr}_{2} \mathrm{Ca}_{2} \mathrm{Cu}_{3} \mathrm{O}_{y}$ composition. Physica C 173, 476-486 (1991)

13. Xianhui, C., et al.: Preparation and superconductivity of the high$T_{\mathrm{c}}$ phase of $\mathrm{Pb}$-doped $\mathrm{Bi}-\mathrm{Sr}-\mathrm{Ca}-\mathrm{Cu}-\mathrm{O}$ superconductor. Solid State Commun. 71(2), 117-119 (1989)

14. Maeda, H., Togano, K.: Bismuth-Based High-Temperature Superconductors. Mercel Dekker, New York (1996) 
15. Quidwal, A.A., et al.: Synthesis and $\mathrm{X}$-ray powder diffraction analysis of high- $T_{\mathrm{c}}$ superconducting $\mathrm{Bi}_{1.6} \mathrm{~Pb}_{0.4} \mathrm{Sr}_{2} \mathrm{Ca}_{2} \mathrm{Cu}_{3} \mathrm{O}_{\delta}$ systems with $x=1$ and 2. Supercond. Sci. Technol. 5, 603-606 (1993)

16. Kocabaş, K., et al.: The effect of Ag substitution of $\mathrm{Cu}$ in BPSCCO superconductors. Balk. Phys. Lett. 8(1), 26-32 (2000)

17. Yang, X., Chaki, T.K.: Hot rolling of $\mathrm{Bi}_{1.6} \mathrm{~Pb}_{0.4} \mathrm{Sr}_{2} \mathrm{Ca}_{2} \mathrm{Cu}_{3} \mathrm{O}_{x}$ superconducting pellets. Supercond. Sci. Technol. 6, 343-348 (1993)

18. Kocabaş, K., Çiftçioğlu, M.: The effect of $\mathrm{Sb}$ substitution of $\mathrm{Cu}$ in $\mathrm{Bi}_{1.7} \mathrm{~Pb}_{0.3} \mathrm{Sr}_{2} \mathrm{Ca}_{2} \mathrm{Cu}_{3-x} \mathrm{Sb}_{x} \mathrm{O}_{y}$ superconductors. Phys. Status Solidi (a) 177, 539-545 (2000)

19. Dou, S.X., et al.: The interaction of $\mathrm{Ag}$ with $\mathrm{Bi}-\mathrm{Pb}-\mathrm{Sr}-\mathrm{Ca}-\mathrm{Cu}-\mathrm{O}$ superconductor. Physica C 160, 533-540 (1989)
20. Matsushita, T., et al.: The effect of Ag on the superconductivity of $\mathrm{Bi}_{2-x} \mathrm{~Pb}_{x} \mathrm{Ca}_{2} \mathrm{Cu}_{3} \mathrm{O}_{y}$ superconductors prepared by an optimum thermal procedure. Supercond. Sci. Technol. 7, 222-226 (1994)

21. Khan, M.N., Khizar, M.: Effect of rare-earth $(\mathrm{Eu}, \mathrm{Yb}$ and $\mathrm{Ag}$ ) substitutions on superconducting properties of the $\mathrm{Bi}_{1.7} \mathrm{~Pb}_{0.3} \mathrm{Sr}_{2} \mathrm{Ca}_{2-x} \mathrm{R}_{x} \quad(\mathrm{R}=\mathrm{Eu}, \mathrm{Yb}$ and $\mathrm{Ag}) \mathrm{Cu}_{3} \mathrm{O}_{y}$ system. J. Mater. Sci. 34, 5833-5838 (1999)

22. Rojek, A., et al.: $115 \mathrm{~K}$ superconductivity in $\mathrm{B}-\mathrm{Pb}-(\mathrm{Ag}, \mathrm{Nb}$, $\mathrm{Sb})-\mathrm{Sr}-\mathrm{Ca}-\mathrm{Cu}-\mathrm{O}$ systems. Solid State Commun. 72(1), 113-116 (1989)

23. Mishra, D.R., et al.: Superconductivity of Nb-substituted Bi-2223 superconductor. Physica C 304, 293-306 (1998)

24. Eremina, E.A., et al.: Influence of boron-containing dopants on the formation superconducting phase in the system $\mathrm{Bi}(\mathrm{Pb})-\mathrm{Sr}-$ $\mathrm{Ca}-\mathrm{Cu}-\mathrm{O}$. Supercond. Sci. Technol. 11, 223-226 (1998) 